\title{
Bosentan inhibits cigarette smoke-induced endothelin receptor expression in pulmonary arteries
}

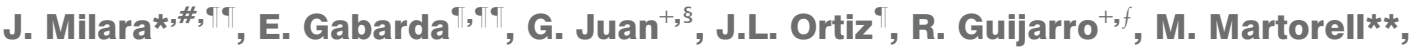 \\ E.J. Morcillo ${ }^{\#, \oplus, \# \#}$ and J. Cortijo*,\#,థ
}

ABSTRACT: The endothelin (ET) system contributes to lung vascular tension and remodelling in smokers and chronic obstructive pulmonary disease (COPD) patients.

This study examined the effect of cigarette smoke (CS) on ET receptor A (ETA) and B (ETB) expression in human pulmonary artery smooth muscle cells (HPASMCs) and human small intrapulmonary arteries, as well as their functional consequences.

CS extract (CSE) increased ETA and ETB expression in HPASMCs and small intrapulmonary arteries, which was attenuated by bosentan, the ETA antagonist BQ123 and the ETB antagonist $B Q 788$, and by blocking ET-1 with a monoclonal antibody against ET-1, suggesting a feed-forward mechanism mediated by ET-1 release. ET receptor (ETR) antagonism attenuated the CSE-induced HPASMC proliferation. Furthermore, CSE exposure increased the acute ET-1-induced small intrapulmonary artery contraction, which was attenuated by bosentan, BQ123 and BQ788. Pulmonary arteries from smokers and COPD patients showed a higher expression of ETA and ETB than those of nonsmoker patients.

These results show a novel mechanism by which ETR blockade attenuates CS-induced ETR overexpression and, subsequently, small intrapulmonary artery tension. These data may be of potential value to explain therapeutic effects of bosentan in some forms of disproportionate pulmonary hypertension in COPD patients.

KEYWORDS: Bosentan, cigarette smoke, endothelin receptor, human pulmonary artery smooth muscle cells, precision-cut lung slice

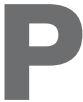
ulmonary hypertension $(\mathrm{PH})$ is a relatively common form of cigarette smoke (CS)induced lung disease. PH develops in $\sim 6 \%$ of subjects with chronic obstructive pulmonary disease (COPD) but is present in $\sim 40 \%$ of patients with a forced expiratory volume in $1 \mathrm{~s}$ of $<1 \mathrm{~L}[1,2]$. The pathogenesis of PH in COPD is unclear. Current studies suggest that $\mathrm{PH}$ is caused by the direct effects of CS on the intrapulmonary vessels by the secretion of a number of vasoconstrictive/proliferative peptides, such as endothelin (ET) or vascular endothelial growth factor, which subsequently contribute to vascular remodelling and the development of $\mathrm{PH}$ [3]. The circulating levels of ET-1 are elevated after exposure to CS in humans [4] and it has been shown that ET-1 correlates with pulmonary systolic pressure in COPD patients with $\mathrm{PH}$ [5], suggesting that ET-1 is involved in CS-induced vascular remodelling. ET-1 activates two receptors, ETA and ETB, which are located in pulmonary artery smooth muscle cells (PASMCs), whilst exclusively ЕТв are present in endothelial cells. Both ETA and ЕTв mediate proliferation and contractility in PASMCs from small pulmonary arteries, while endothelial ETв mediates vasodilation in normal pulmonary arteries. ETB upregulation has been observed in human blood vessels from patients with ischaemic heart disease [6], hypertension [7] and severe $\mathrm{PH}$ [8]. More recently, it has been shown that CS extract (CSE) induces ETA and ЕTв overexpression in resistant cerebral arteries from rats by a mechanism implicating the activation of the intracellular mitogen-activated protein kinases (MAPK) extracellular signalregulated kinase (ERK) $1 / 2$ and p38, the transcription factor nuclear factor (NF)- $\mathrm{\kappa B}$, and c-Jun N-terminal kinase (JNK) [9-11].

\section{AFFILIATIONS}

*Clinic Research Unit,

${ }^{\S}$ Respiratory Unit,

${ }^{f}$ Thoracic Surgery Unit,

**Dept of Pathology, University

General Hospital Consortium,

${ }^{\#}$ CIBERES, Health Institute Carlos III,

"Depts of Pharmacology,

+Medicine, Faculty of Medicine,

University of Valencia,

\#\#Clinical Pharmacology Unit,

University Clinic Hospital, Valencia, Spain.

"These authors contributed equally

to this work

CORRESPONDENCE

J. Milara

Unidad de Investigación

Consorcio Hospital General

Universitario

Avenida tres cruces $\mathrm{s} / \mathrm{n}$

E-46014 Valencia

Spain

E-mail: xmilara@hotmail.com

Received:

Feb 042011

Accepted after revision:

July 252011

First published online:

Aug 042011 
The data suggest that the upregulation of ET receptors (ETRs) is an important molecular mechanism that could play an essential part in the development of pathological lung arteries secondary to CS, such as intimal thickening, vessel narrowing and $\mathrm{PH}$. Therefore, therapeutic interventions focused on inhibiting ETR expression could be of potential value to ameliorate pulmonary artery remodelling and tension in smokers with COPD. Currently, no data exist concerning the effect of CS on ETR expression in human PASMCs (HPASMCs) and human small intrapulmonary arteries, and on the effect of ETR antagonists on the regulation of ETR.

This study was conducted to analyse the effect of CS on ETR expression and ET release in HPASMCs and small intrapulmonary arteries, as well as the consequences of ETR upregulation on HPASMC proliferation and small intrapulmonary artery tension. Furthermore, we studied whether ETR antagonism may attenuate ETR expression induced by CS and their functional consequences. We found that the dual ETR antagonist bosentan partially suppressed the CS-induced ET system activation in HPASMCs and small intrapulmonary arteries, as well as its functional consequences. These data may be of potential value to explain therapeutic effects of bosentan in some forms of disproportionate PH in smokers with COPD.

\section{METHODS}

See the online supplement for further details of the methods used.

\section{Patients}

A total of six nonsmoker controls, seven smokers and eight COPD patients were included in the study. All lung tissues studied were taken from uninvolved lung tissue during lobectomy resection for malignant lesions. Samples of distal lung, located as far away as possible from the tumour, were chosen for the study. Pulmonary function tests (forced spirometry) and arterial blood gas measurements were performed during the days prior to surgery. None of the patients exhibited clinical evidence of PH. HPASMCs for in vitro experiments were isolated from 2-3-mm pulmonary arteries of nonsmoker lung tissue. Precision-cut lung slices with small intrapulmonary arteries (internal diameter 100$300 \mu \mathrm{m})$ were prepared from nonsmoker lung tissue. Isolated pulmonary arteries of internal diameter $0.5-1.0 \mathrm{~mm}$ were used to measure ETR expression in nonsmokers, smokers and COPD patients. The protocol was approved by the local research and independent ethics committee of the University General Hospital of Valencia (Valencia, Spain). Informed written consent was obtained from each participant. Clinical features of patients are defined in table 1 .

\section{Isolation and culture of HPASMCs}

Tumour-free material from surgical specimens of nonsmoker patients was used. HPASMCs were isolated from surgical specimens of human pulmonary arteries as previously outlined [12]. Briefly, segments of pulmonary artery (internal diameter 2-3 mm) were digested with 1\% collagenase (Gibco, Paisley, UK) in RPMI-1640 culture medium for $30 \mathrm{~min}$ at $37^{\circ} \mathrm{C}$. HPASMCs were isolated from human pulmonary artery endothelial cells (HPAECs) by means of CD31-coated Dynabeads (Dynal Biotech, Darmstadt, Germany) as previously outlined [12] and cultured in Dulbecco's modified Eagle's medium (DMEM) supplemented with 10\% fetal calf

\begin{tabular}{|c|c|c|c|}
\hline & Nonsmokers & Smokers & COPD \\
\hline Subjects $\mathbf{n}$ & 6 & 7 & 8 \\
\hline Age yrs & $66 \pm 5$ & $68 \pm 7$ & $67 \pm 9$ \\
\hline $\begin{array}{l}\text { Tobacco consumption } \\
\text { pack-yrs }\end{array}$ & 0 & $30 \pm 3$ & $40 \pm 8$ \\
\hline FEV $1 \%$ pred & $92 \pm 3$ & $90 \pm 6$ & $68 \pm 8$ \\
\hline FVC \% pred & $94 \pm 4$ & $93 \pm 8$ & $87 \pm 6$ \\
\hline 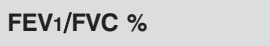 & $89 \pm 5$ & $87 \pm 7$ & $63 \pm 5$ \\
\hline TLC \%pred & $90 \pm 6$ & $88 \pm 3$ & $97 \pm 4$ \\
\hline $\mathrm{Pa}, \mathrm{O}_{2}, \mathrm{mmHg}$ & $90 \pm 8$ & $85 \pm 7$ & $84 \pm 6$ \\
\hline $\mathrm{Pa}, \mathrm{CO}_{2} \mathrm{mmHg}$ & $37 \pm 6$ & $39 \pm 3$ & $41 \pm 3$ \\
\hline \multicolumn{4}{|c|}{$\begin{array}{l}\text { Data are presented as mean } \pm \text { SEM, unless otherwise stated. COPD: chronic } \\
\text { obstructive pulmonary disease; FEV1: forced expiratory volume in } 1 \mathrm{~s} \text {; \% pred: } \\
\% \text { predicted; FVC: forced vital capacity; TLC: total lung capacity; } \mathrm{Pa}_{1} \mathrm{O}_{2} \text { : arterial } \\
\text { oxygen tension; } \mathrm{Pa}_{2} \mathrm{CO}_{2} \text { : arterial carbon dioxide tension. }\end{array}$} \\
\hline
\end{tabular}

serum, $1 \%$ fungizone and $2 \%$ streptomycin/penicillin. All HPASMCs studied were used from passage 1 to 4 .

\section{Real time RT-PCR}

Real-time RT-PCR was performed as previously outlined [13]. In brief, total RNA was isolated from cultured HPASMCs using TriPure ${ }_{\circledast}$ Isolation Reagent (Roche, Indianapolis, IN, USA). cDNA was amplified with specific primers for ETB and ETA (pre-designed by Applied Biosystems, Foster City, CA, USA; ETB: catalogue number Hs00240747_m1; ETA: catalogue number Hs03988672_m1) and glyceraldehyde phosphate dehydrogenase (GAPDH) (pre-designed by Applied Biosystems; catalogue number 4352339E) as a housekeeping gene. Relative quantification of these different transcripts was determined with the $2^{-\Delta \Delta C t}$ method using GAPDH as the endogenous control and normalised to the control group.

\section{Western blot}

Protein extraction from HPASMCs, human lung precisioncut slices, and pulmonary artery tissues from nonsmokers, smokers and COPD patients were tested for ETB (50 kDa), ETA (54 kDa), phosphorylated ERK1/2 (42-44 kDa) and $\beta$-actin (42 kDa) using immunodetection Western blot as previously outlined [13, 14]. Details are given in the supplementary material online, in the Expanded Methods section.

\section{Preparation of CSE solutions}

CSE was prepared as previously reported [13]. Briefly, the smoke of a research cigarette (2R4F; University of Kentucky, Lexington, KY, USA) was generated by a respiratory pump and bubbled into a flask containing $25 \mathrm{~mL}$ DMEM. The resulting CSE solution was deemed to be $100 \%$ CSE and was used for experiments within $30 \mathrm{~min}$ of preparation.

To test for cytotoxicity from CSE, HPASMCs were treated with CSE concentrations of up to $10 \%$ for 24 and $48 \mathrm{~h}$. No significant difference in the supernatant lactate dehydrogenase level (Lactate Dehydrogenase Cytotoxicity Assay; Cayman Chemical, Madrid, Spain) was observed, compared with the control group (data not shown). 


\section{Intracellular free calcium measurements}

Intracellular free calcium concentration $\left(\left[\mathrm{Ca}^{2+}\right]_{\mathrm{i}}\right)$ was measured by fluorescence microscopy (TE200; Nikon, Tokyo, Japan) in HPASMCs using the calcium indicator dye fura-2 as previously outlined [13-15]. The fura-2 fluorescence ratio was recorded every $0.1 \mathrm{~s}$ using a Lambda 10-2 Sutter Instrument (Nikon) and fluorescence analysis was performed with the Metafluor 5.0 software (Molecular Devices, Sunnyvale, CA, USA). $\left[\mathrm{Ca}^{2+}\right]_{i}$ was calculated by ratiometric analysis as previously mentioned [13].

\section{Cell contraction}

Contraction of HPASMCs in response to ET-1 was studied by traction microscopy as previously outlined [13]. Collagencoated polyacrylamide gels with embedded fluorescent microbeads (diameter $200 \mathrm{~nm}$ ) were used. Gel disks with cultured HPASMCs were incubated for $24 \mathrm{~h}$ in the absence (control) or presence of $10 \%$ CSE, alone or in combination (30 min before CSE) with a bosentan $(10 \mu \mathrm{M})$, BQ788 $(10 \mu \mathrm{M})$ and BQ123 $(10 \mu \mathrm{M})$. Later, gel disks with cultured HPASMCs were visualised with a microscope using bright-field illumination. After 7 min of baseline recording, ET-1 (10 nM) was added and fluorescent images were acquired for an additional $12 \mathrm{~min}$. Traction forces exerted by the cell on the substrate were computed from the displacement field of the gel substrate.

\section{Cell proliferation assay}

HPASMC proliferation was measured by colorimetric immunoassay based on bromodeoxyuridine (BrdU) incorporation during DNA synthesis using a cell proliferation ELISA BrdU kit (Roche, Mannheim, Germany) as previously outlined [14].

\section{Rho activity and ET assays}

A commercially available, ELISA-based RhoA-GTP activity assay (G-LISA; Cytoskeleton, Denver, CO, USA) was used to measure the relative RhoA-GTP activity of serum-starved HPASMCs after experimental treatments as previously outlined [13]. ET was measured in HPASMC culture supernatants by enzyme immunoassay kit (Cayman Chemical) according to the manufacturer's protocol.

\section{Dichlorofluorescein diacetate fluorescence measurement of reactive oxygen species}

Intracellular reactive oxygen species (ROS) levels $\left(\mathrm{H}_{2} \mathrm{O}_{2}\right.$ and superoxide anion) were measured in HPASMCs by means of dichlorofluorescein (DCF) diacetate as previously outlined [13]. Cells were treated with bosentan $(10 \mu \mathrm{M})$, BQ788 $(10 \mu \mathrm{M})$ or BQ123 $(10 \mu \mathrm{M}) 30 \mathrm{~min}$ prior to the addition of $10 \%$ CSE and incubated for $24 \mathrm{~h}$.

At the end of the incubation period, cells were washed twice with PBS and fluorescence was measured using a microplate spectrophotometer (Victor 1420; PerkinElmer, Madrid, Spain). Results were expressed as DCF fluorescence in relative fluorescence units. Representative images of each condition were captured via fluorescence microscopy.

\section{Immunofluorescence}

Precision-cut human lung slices were incubated in the presence or absence of bosentan, BQ788 or BQ123 for $1 \mathrm{~h}$ and stimulated with $10 \%$ CSE for $24 \mathrm{~h}$. Then, lung slices were washed three times with PBS and fixed (4\% paraformaldehyde for $4 \mathrm{~h}$ at room temperature). Slices were embedded in $\mathrm{OCT}^{\mathrm{TM}}$ Compound (Tissue-Tek ${ }_{\mathbb{R}}$, Alphen aan den Rijn, the Netherlands) and immunostained with ETA and ETB antibodies followed by the application of a secondary rhodamineconjugated antibody. A comparative study of the autofluorescence of the internal and external elastic lamina enabled the distinction between endothelial and smooth muscle cells (SMCs) in small intrapulmonary arteries.

\section{Preparation of precision-cut lung slices from resected human lung}

Precision-cut lung slices were obtained as previously outlined [16] with minor modifications. Briefly, 3\% (w/v) ultralow melting point agarose (Sigma, Poole, UK) was injected into the lung tissue, which was cut into precision-cut slices using a Krumdieck tissue slicer (model MD4000; Alabama Research and Development, Munford, AL, USA) with the slice thickness set at 260-300 $\mu \mathrm{m}$. We carefully chose only small arteries that were adjacent to identifiable small airways. Sections were placed in fresh medium and incubated in the presence or absence of bosentan $(10 \mu \mathrm{M})$, BQ788 $(10 \mu \mathrm{M})$ or BQ123 $(10 \mu \mathrm{M})$ for $1 \mathrm{~h}$ prior to stimulation with or without $10 \%$ CSE for $24 \mathrm{~h}$. The slice was visualised using a microscope (Eclipse TE200, Nikon; magnification $\times 40$ ) connected to a live charge-coupled device camera (CoolSNAPfx; Photometrics, Tucson, AZ, USA). After washout (30 $\mathrm{min}$ ), $80 \mathrm{mM} \mathrm{KCl}$ was perfused for $5 \mathrm{~min}$ to establish the maximal contractile response (100\%). After rinsing and equilibration (normally $10 \mathrm{~min}$ of perfusion), the lowest concentration of ET- 1 needed to begin the concentration response $\left(10^{-9}-10^{-6} \mathrm{M}\right)$ was administered. Small pulmonary artery contraction was continuously monitored and was expressed as a percentage of the maximal reduction of area obtained with $\mathrm{KCl}$. Artery lumen area was measured using MetaMorph software (Molecular Devices) and given in units of square micrometres. Results were expressed as \% of $\mathrm{KCl}$ area. A log half-maximal effective concentration (EC50) value and maximum drug effect (Emax) value for each artery was derived from a concentration-response curve. Details are given in the supplementary material online, in the Expanded Methods section.

\section{Analysis of results}

All values are reported as mean \pm SEM. Determinations were performed in duplicate and at least three independent experiments were performed for each set of conditions. Twogroup comparisons were analysed using the two-tailed paired t-test for dependent samples, or unpaired t-test for independent samples. Multiple comparisons were analysed by oneway ANOVA followed by the Student-Newman-Keuls post hoc test. For all procedures, $\mathrm{p}$-values of $<0.05$ were considered statistically significant.

\section{RESULTS \\ CSE-induced ETB and ETA upregulation is prevented by bosentan}

In vitro exposure of HPASMCs to CSE elicited a dose- and time-dependent increase of the ETA and ETB protein and mRNA expression (fig. $1 \mathrm{a}$ and b), reaching a peak value at $10 \%$ CSE after $24 \mathrm{~h}$ of stimulation. Based on these results, we selected $10 \%$ CSE for $24 \mathrm{~h}$ as the stimulation condition for later studies. Pre-incubation of HPASMCs with bosentan (10 nM to $10 \mu \mathrm{M})$ dose-dependently prevented ETA and ETB protein 
a)
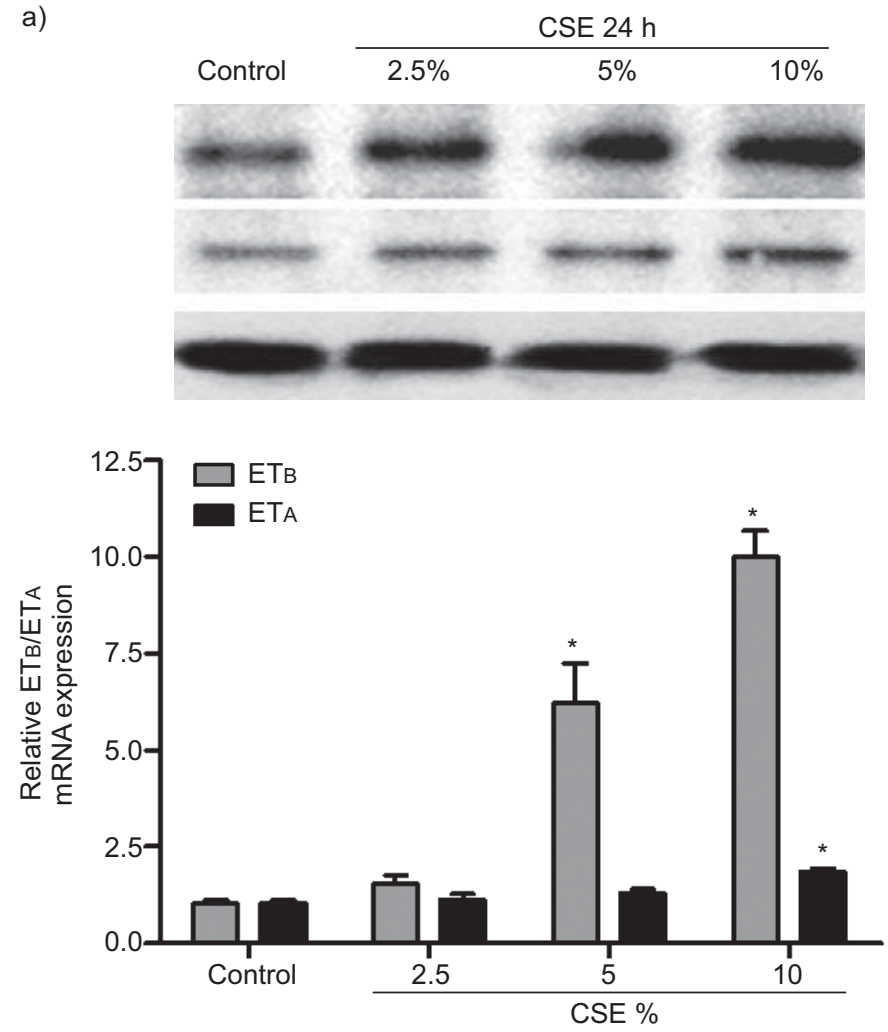

c)

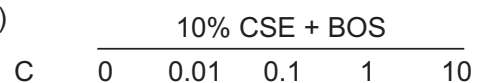

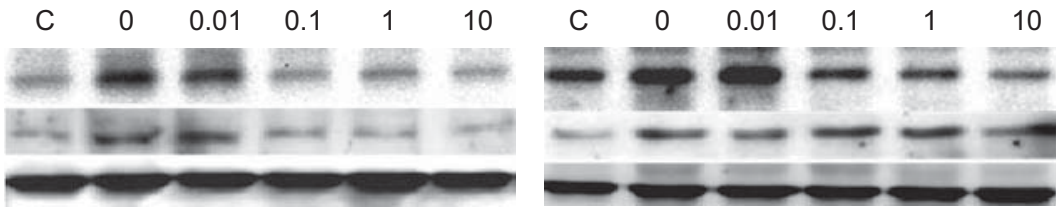

b)
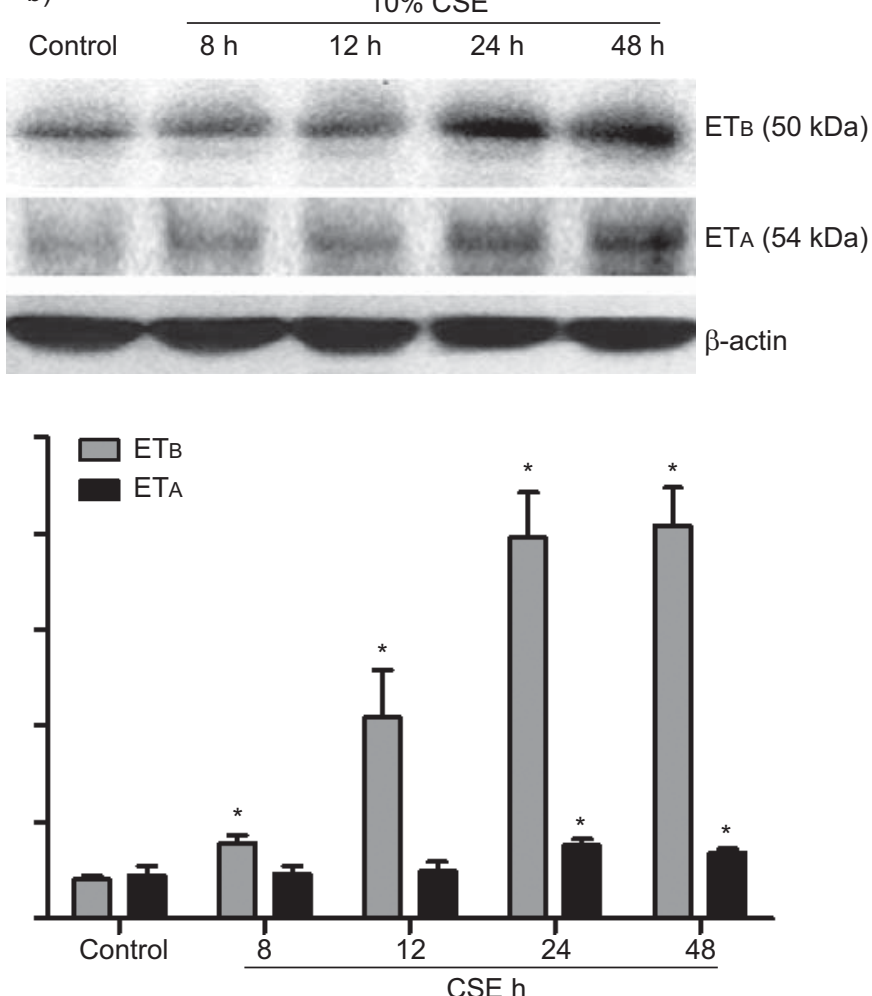

e)

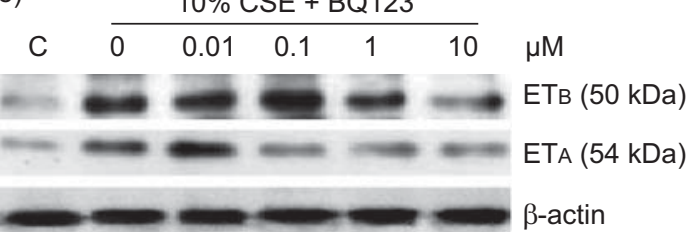

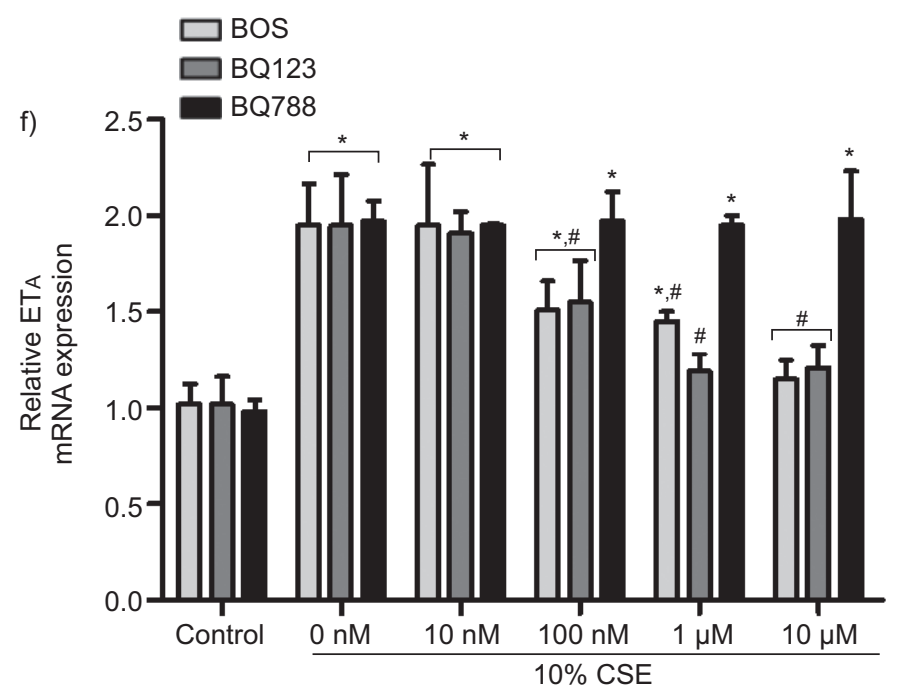

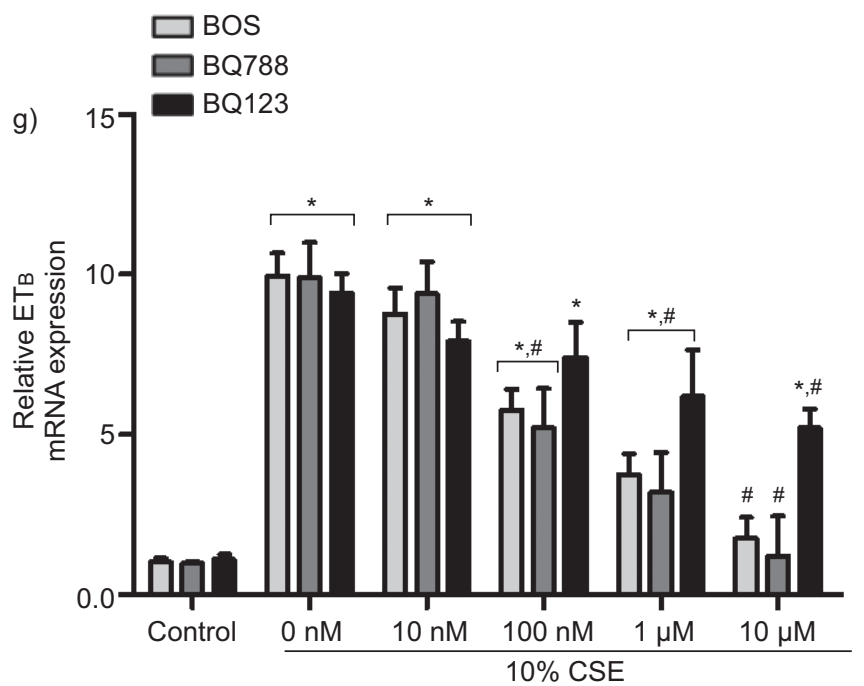

FIGURE 1. Cigarette smoke increases endothelin receptor $A$ and B (ETA and ETB, respectively). Cigarette smoke extract (CSE) a) dose- and b) time-dependently increased ETB and ETA protein and mRNA expression in human pulmonary artery smooth muscle cells. c) Bosentan (BOS), d) BQ788 and e) BQ123 dose-dependently prevented the CSE-induced ETB protein expression, while only BOS and BQ123 dose-dependently prevented ETA expression. f) BOS and BQ123 dose-dependently prevented the CSE-induced ETB and ETA gene expression. g) BOS, BQ123 and BQ788 dose-dependently prevented the CSE-induced ETA expression. Data are presented as mean \pm SEM of three independent experiments per condition. *: $p<0.05$ compared with respective control $(C)$ condition; * $p<0.05$ compared with CSE group. 
upregulation (fig. 1c). The selective ETB antagonist BQ788 prevented the CSE-induced ЕTB upregulation at concentrations of 1 and $10 \mu \mathrm{M}$ concentrations, while no effect was observed on CSE-induced ETA upregulation (fig. 1d). In contrast, the selective ETA antagonist BQ123 successfully prevented ETA upregulation at $100 \mathrm{nM}$ to $10 \mu \mathrm{M}$ and ETB upregulation at 1 and $10 \mu \mathrm{M}$ (fig. 1e). Studies performed on mRNA expression showed the same results as those observed for protein expression (fig. 1f and g).

CSE-induced ETB and ETA expression is partially mediated by ERK1/2, RhoA-GTP and intracellular ROS downstream pathways, as well as by an autocrine ET-1 feed-forward mechanism

Incubation of HPASMCs with the ERK1/2 inhibitor PD98059 $(10 \mu \mathrm{M})$, the Rho-kinase inhibitor Y27632 $(10 \mu \mathrm{M})$ or with the antioxidant $\mathrm{N}$-acetylcysteine (NAC) $(1 \mathrm{mM})$ effectively prevented ETB and ETA protein overexpression induced by CSE (fig. 2a). Likewise, HPASMC incubation with a monoclonal antibody to ET-1 $\left(10 \mu \mathrm{g} \cdot \mathrm{mL}^{-1}\right)$ also suppressed CSE-induced ETB and ETA overexpression (fig. 2a). In other experiments, ET-1 (10 nM) addition ( $24 \mathrm{~h})$ increased ETB and ETA protein expression (fig. $2 \mathrm{~b})$. Bosentan $(10 \mu \mathrm{M}), \mathrm{BQ} 123 \quad(10 \mu \mathrm{M})$, PD98059, Y27632 or NAC partially prevented the ET-1-induced ETB and ETA protein expression whilst BQ788 $(10 \mu \mathrm{M})$ only prevented ЕTB overexpression (fig. 2b). These results were in keeping with ETB and ETA gene expression (fig. 2c). Interestingly, 10\% CSE (24 h) significantly increased supernatant ET levels $(\mathrm{p}<0.05$ versus control; fig. $2 \mathrm{~d})$, which was prevented by bosentan, BQ788, BQ123, PD98059, Y27632 and NAC (1 mM) (fig. 2d).

\section{CSE-induced intracellular ROS, ERK1/2 phosphorylation and RhoA-GTP activation is prevented by bosentan.}

CSE increased the intracellular fluorescence intensity derived from DCF formation by $\sim 2.73$-fold after $24 \mathrm{~h}$. Bosentan and BQ123 significantly reduced the CSE-induced ROS formation by $\sim 1.17$ - and $\sim 1.5$-fold, respectively, while BQ788 did not reach a significant reduction ( $\sim 2.23$-fold) (fig. $3 a$ and $b$ ) over the control group. Furthermore, CSE increased ERK1/2 phosphorylation and RhoA-GTP activation after $24 \mathrm{~h}$, which was effectively prevented by bosentan, BQ123 and, to a lesser extent, by BQ788 (fig. 3c and d).

\section{Bosentan prevents CSE-induced HPASMC proliferation}

CSE increased cell proliferation by $\sim 2$-fold (fig. 4a). Bosentan inhibited cell proliferation while BQ123 and BQ788 reduced proliferation by $\sim 1.31$ - and $\sim 1$.6-fold over control respectively (fig. 4). Moreover, PD98059, Y27632 and NAC (1 mM) also prevented cell proliferation. Since it has been shown that CSE increases supernatant ET levels, we selectively blocked ET-1 with ET-1 monoclonal antibody, which subsequently reduced cell proliferation to basal levels (fig. 4a). Since HPASMC proliferation in vivo is mainly mediated by growth factors, such as platelet-derived growth factor (PDGF), we treated cells with CSE in presence or absence of human recombinant PDGF$\mathrm{BB}$ at $10 \mathrm{ng} \cdot \mathrm{mL}^{-1}$. PDGF-BB increased cell proliferation 3.1 -fold in the absence of CSE and 3.5-fold in the presence of CSE. Bosentan, BQ123 and BQ788 inhibited cell proliferation induced by CSE and PDGF-BB 1.6-, 1.9- and 2.1-fold, respectively (fig. $4 \mathrm{~b}$ ).

\section{HPASMC exposure to CSE increases the ET-1-induced $\left[\mathrm{Ca}^{2+}\right]_{i}$ and cell contraction}

HPASMCs exposed to $10 \%$ CSE were subject to an acute increase in $10 \mathrm{nM}$ ET-1-induced $\left[\mathrm{Ca}^{2+}\right]_{\mathrm{i}}$ with a mean \pm SEM peak value of $493 \pm 46$ versus $274 \pm 34 \mathrm{nM}$ for untreated cells (control) ( $<<0.05$; fig. $5 \mathrm{a}$ and $\mathrm{b})$. Bosentan, BQ788 or BQ123 added before and during CSE exposure reduced the acute ET-1-induced peak increase in $\left[\mathrm{Ca}^{2+}\right]_{\mathrm{i}}$ to $304 \pm 41,395 \pm 36$ and $343 \pm 32 \mathrm{nM}$, respectively ( $\mathrm{p}<0.05$ versus CSE alone; fig. 5a and b). ET-1 (10 nM) increased cell contraction and was significantly higher in those cells exposed to CSE (10\%) versus unexposed cells $(p<0.05$; fig. $5 c)$. Cells pre-treated with CSE in the presence of bosentan, BQ788 or BQ123 were less susceptible to ET-1-induced cell contraction, as their cell contraction was near to control levels (fig. 5c).

\section{CSE exposure increases ET-1-induced human small intrapulmonary artery contraction, which is prevented by bosentan}

Precision-cut lung slices incubated with CSE showed an increase of ETB protein expression, which was significantly prevented by bosentan, BQ788 and BQ123, while CSE-induced ETA protein expression was only prevented by bosentan and BQ123 (fig. 6a). These results were qualitatively reproduced by immunofluorescence experiments (fig. 6b). In this regard, CSE exposure increased the ETB fluorescence intensity in endothelial cells and SMCs. ETA fluorescence intensity was augmented only in the area of SMCs. Precision-cut lung slices pre-treated with bosentan showed lower fluorescence intensity for both ETB and ETA (fig. 6b). Precision-cut lung slices pre-treated with 10\% CSE increased vascular sensitivity to ET-1. The calculated log EC50 for the CSE treated group was $-9.36 \pm 0.32$ versus $-8.47 \pm 0.16 \mathrm{M}$ in controls $(p<0.05$; fig. $6 c$ and $d)$. Precision-cut lung slices exposed to CSE in presence of bosentan, BQ788 or BQ123 significantly increased the ET-1 $\log$ EC50 to $-8.76 \pm 0.3$, $-8.73 \pm 0.17$ and $-8.64 \pm 0.24 \mathrm{M}$, respectively. CSE also increased the ET-1 Emax contraction versus the control group $(184 \pm 5.7$ versus $136 \pm 3.6$; $\mathrm{p}<0.05$; fig. $6 \mathrm{f})$, which was attenuated by bosentan, BQ788 or BQ123 pre-treatments to an ET-1 Emax of $127.8 \pm 4.3,160.9 \pm 3.6$ and $145.8 \pm 4.3$, respectively (fig. $6 f$ ). However, pulmonary arteries from smokers and COPD patients showed an increase in ETA and ETB protein expression versus nonsmoker patients $(\mathrm{p}<0.05$; fig. 7$)$.

\section{DISCUSSION}

The relevance of this study is based in two main assumptions: 1) chronic CS exposure is responsible for pulmonary vascular remodelling and $\mathrm{PH}$ development during COPD progression [17]; and 2) the ET system is directly implicated in pulmonary remodelling in COPD patients [18]. The results of this study show that ETR antagonism could attenuate CS-induced HPASMC proliferation and tension, as well as small intrapulmonary artery tension, by means of ETR and ET downregulation, thus suggesting that bosentan could be useful to treat certain forms of $\mathrm{PH}$ in smokers with COPD, as suggested recently $[19,20]$. Furthermore, we provide a novel mechanism of action by which CS increases ETR expression through a feed-forward mechanism mediated by ET release and the activation of ERK1/2, RhoA-GTP and intracellular ROS. All these intracellular pathways were attenuated by bosentan. 
a)
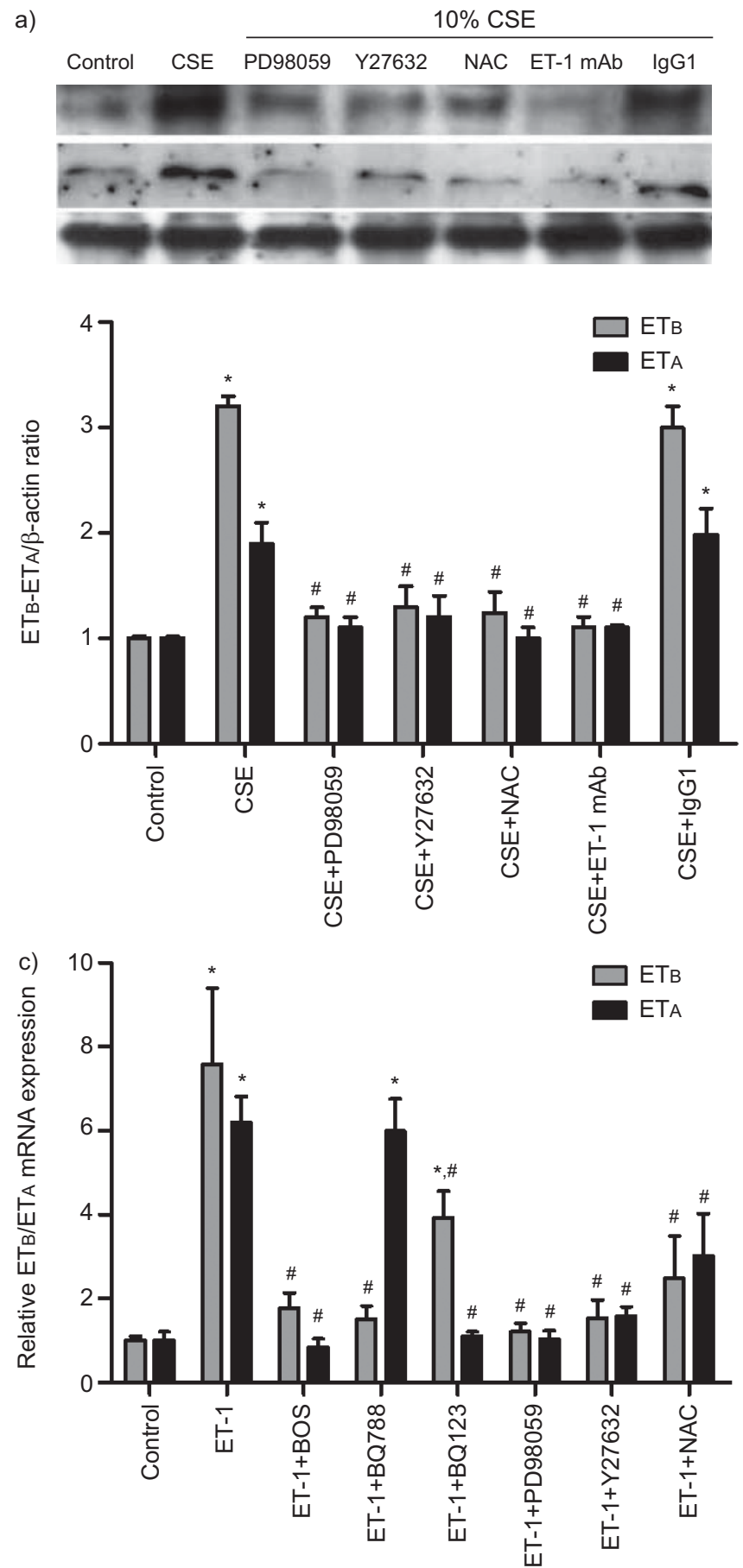

b)
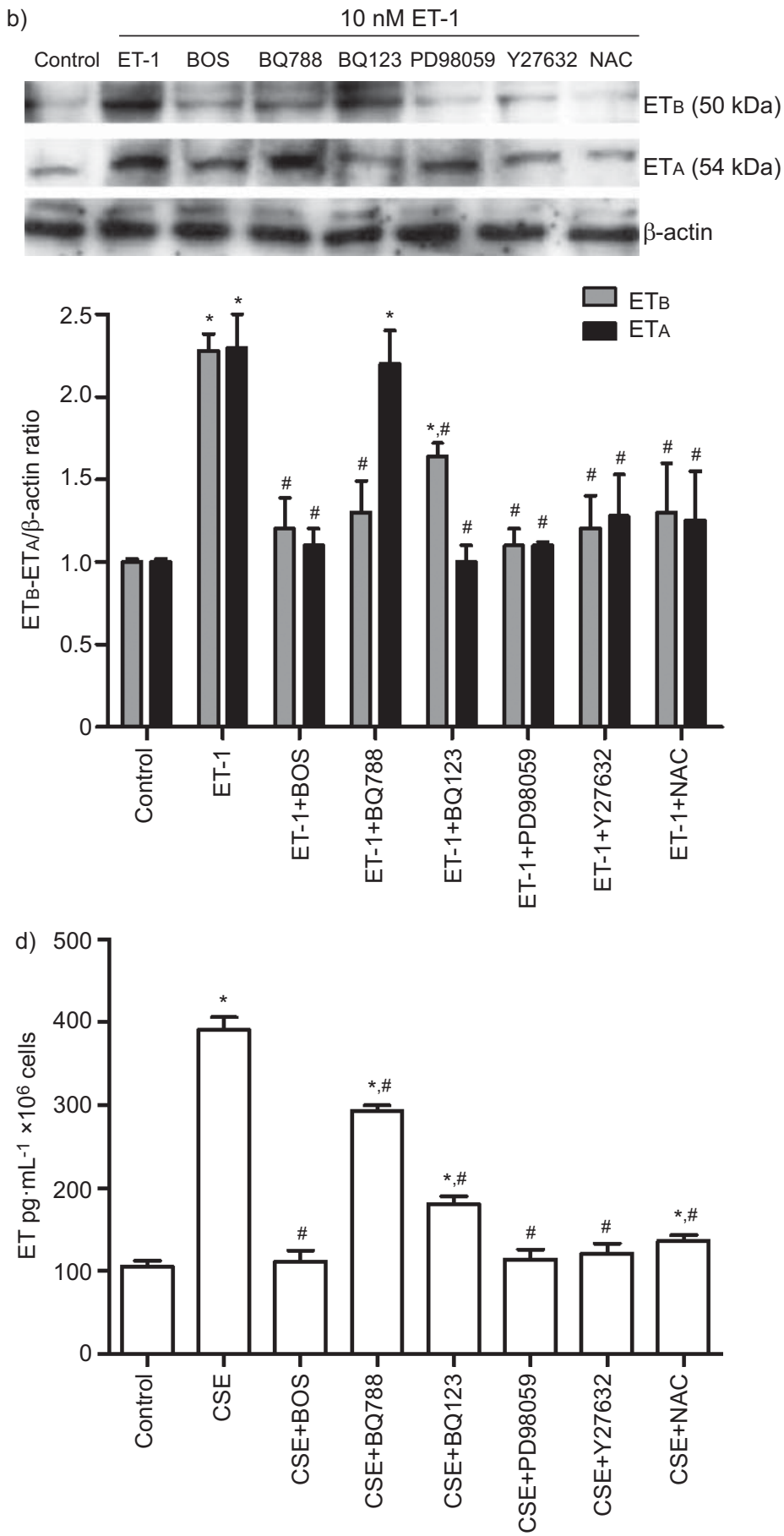

FIGURE 2. Cigarette smoke increases endothelin receptor $A$ and $B$ (ETA and $E T B$, respectively) by a mechanism that implicates intracellular reactive oxygen species, extracellular signal-regulated kinase 1/2, RhoA-GTP and an autocrine endothelin (ET) feed-forward mechanism. a) The increase of ETA and ETB induced by 10\% cigarette smoke extract (CSE) (24 h of incubation) was prevented by PD98059 (10 $\mu \mathrm{M})$, Y27632 (10 $\mu \mathrm{M})$ or $N$-acetylcysteine (NAC) (1 mM) in human pulmonary artery smooth muscle cells. Incubation with ET-1 monoclonal antibody (mAb) $\left(10 \mu \mathrm{g} \cdot \mathrm{mL}^{-1}\right) 30$ min before CSE addition also prevented ETA and ETB upregulation, unlike the negative immunoglobulin (Ig)G1 isotype control. Incubation with $10 \mathrm{nM} \mathrm{ET-1} \mathrm{for} 24 \mathrm{~h}$ significantly increased ETA and ETB b) protein and c) mRNA expression, which was prevented by bosentan (BOS) $(10 \mu \mathrm{M}), \mathrm{BQ} 123(10 \mu \mathrm{M})$, PD98059, Y27632 and NAC, while BQ788 (10 $\mu \mathrm{M})$ only prevented ETB, but not ETA, expression. d) 10\% CSE increased ET release, which was attenuated by BOS, BQ123, BQ788, PD98059, Y27632 and NAC. Data are presented as mean \pm SEM of three independent experiments per condition. *: $p<0.05$ compared with respective control condition; $\#$ : $p<0.05$ compared with CSE group.

Whether our results are applicable to in vivo CS inhalation depends on the assumption that CS components reach the vascular bed of smaller pulmonary arteries. Several observations strengthen this assumption. 1) CS components are rapidly taken up into the bloodstream during smoking ( $\sim 1 \mathrm{~min})$ [21], suggesting rapid equilibration across the gas-exchange surface. 2) Many smoke components are highly water soluble, such as peroxynitrite, which is considered a potent remodelling agent 
a)

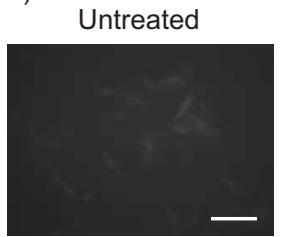

CSE+BQ788

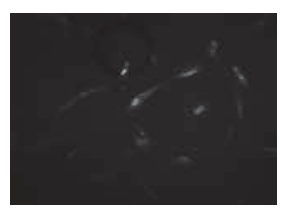

c)
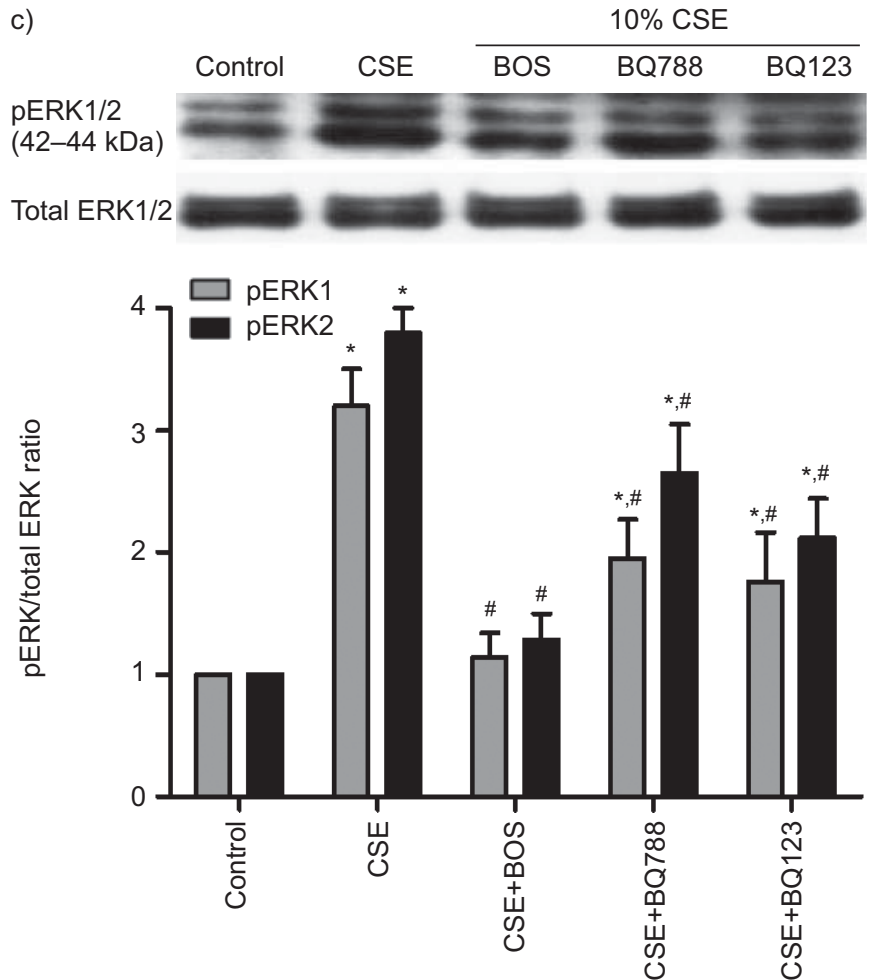
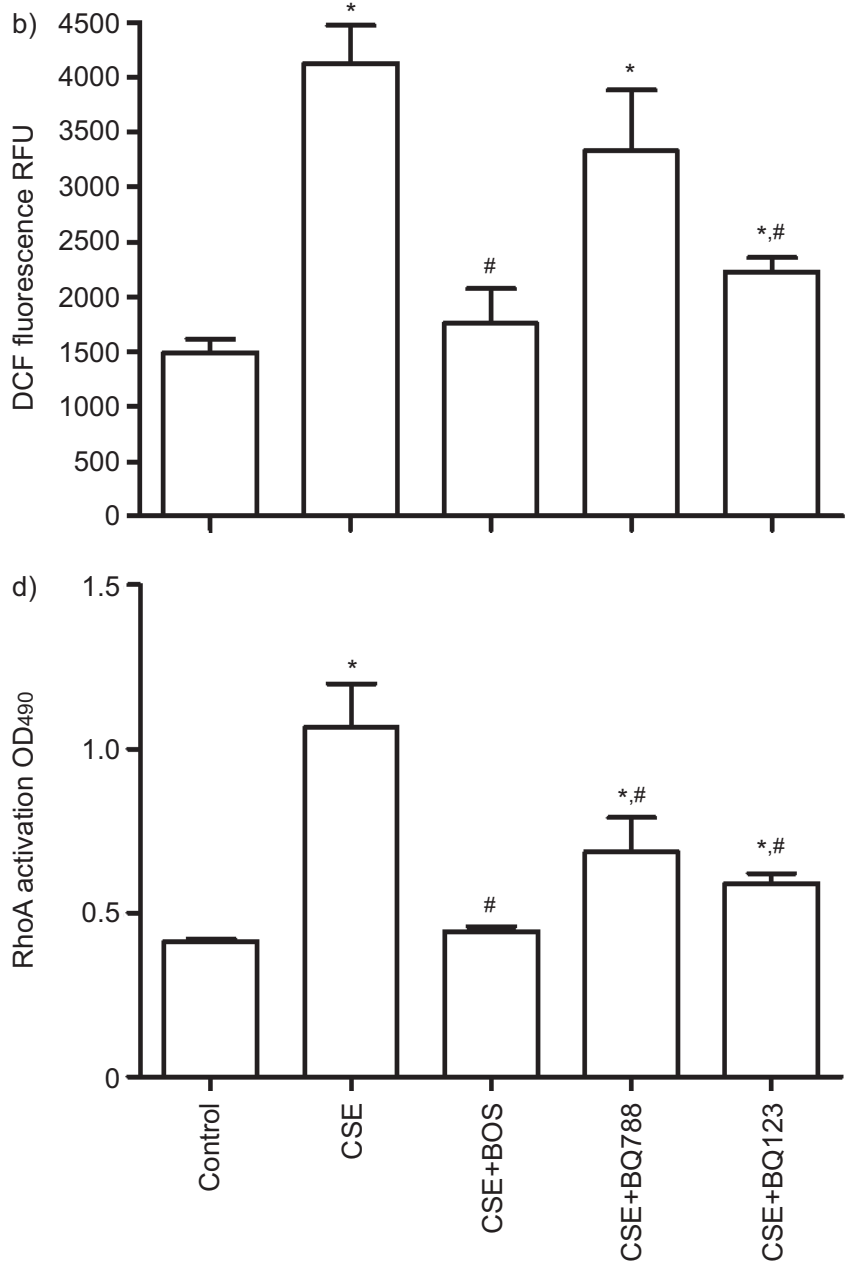

FIGURE 3. Endothelin receptor antagonism attenuates the cigarette smoke extract (CSE)-induced reactive oxygen species (ROS), extracellular signal-regulated kinase (ERK)1/2 phosphorylation and RhoA-GTP activation. a, b) 10\% CSE increases intracellular ROS generation after $24 \mathrm{~h}$ of exposure as assessed by dichlorofluorescein (DCF) fluorescence intensity in human pulmonary artery smooth muscle cells. The CSE-induced ROS generation was suppressed by bosentan (BOS) (10 $\mu \mathrm{M})$ and by BQ123 $(10 \mu \mathrm{M})$ but not by BQ788 $(10 \mu \mathrm{M})$. a) Representative intracellular ROS fluorescence images are presented. Scale bar $=20 \mu \mathrm{m}$. c) 10\% CSE elicited ERK1/2 phosphorylation after $24 \mathrm{~h}$ of exposure, which was suppressed by BOS, attenuated by BQ123 and, to a lesser extent, by BQ788. d) 10\% CSE increased RhoA-GTP activation which was also suppressed by BOS, attenuated by BQ123 and, to a lesser extent, by BQ788. Data are presented as mean \pm SEM of three independent experiments per condition. RFU: relative fluorescence unit; pERK: phosphorylated ERK; OD490: optical density measured at $490 \mathrm{~nm}$. *: $p<0.05$ compared with respective control condition; ${ }^{*}: p<0.05$ compared with CSE group.

in pulmonary arteries [22], allowing easy solution into the alveolar lining and interstitial fluid. 3) Respiratory gas exchange has been demonstrated in pulmonary vessels as large as $3 \mathrm{~mm}$ [23], suggesting that smoke might have access to smaller pulmonary arteries; we obtained the same results in cells obtained from $\sim 3-\mathrm{mm}$ arteries as in small intrapulmonary arteries of $100 \mu \mathrm{m}$ internal diameter (precision-cut lung slice experiments). 4) Smoke components are present in recirculating blood for several hours after smoking [24], allowing continued exposure to the lung vascular bed during recirculation.

The concentration of smoke components around the vascular bed is difficult to estimate. In this study, we used CSE at 2.5$10 \%$ concentration, which may correspond approximately to the exposure associated with smoking 0.5-2 packs per day, as previously outlined [25]; thus, our experiment probably estimated the biological significance of the smoking habit. 

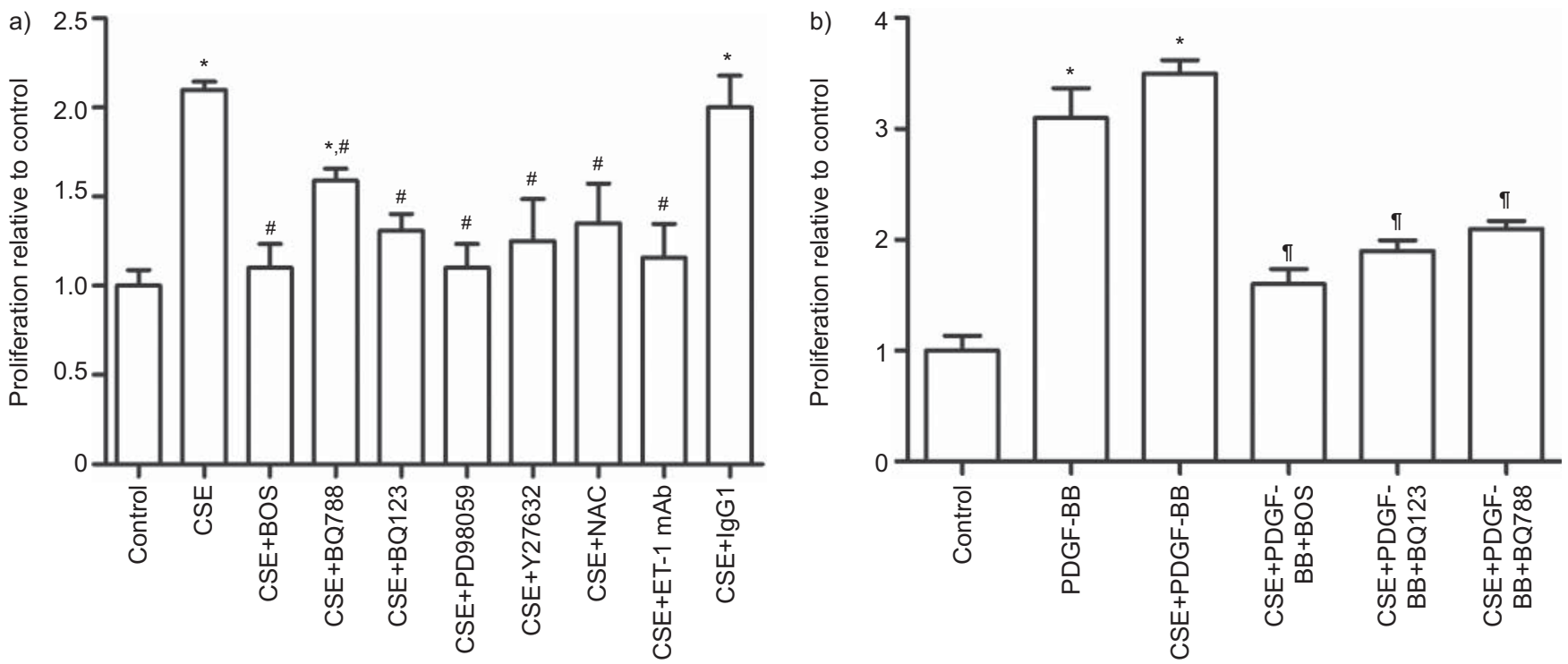

FIGURE 4. Cigarette smoke increases pulmonary artery smooth muscle cell proliferation. a) $10 \%$ cigarette smoke extract (CSE) increased human pulmonary artery smooth muscle cell (HPASMC) proliferation after $24 \mathrm{~h}$ of exposure. Bosentan (BOS) $(10 \mu \mathrm{M}), \mathrm{BQ1} 23(10 \mu \mathrm{M}), \mathrm{BQ788}(10 \mu \mathrm{M}), \mathrm{PD} 98059(10 \mu \mathrm{M}), \mathrm{Y} 27632(10 \mu \mathrm{M}), \mathrm{N}$ acetylcysteine (NAC) (1 mM) and endothelin (ET)-1 monoclonal antibody (mAb) $\left(10 \mu \mathrm{g} \cdot \mathrm{mL}^{-1}\right)$ effectively prevented the CSE-induced HPASMC proliferation. b) plateletderived growth factor (PDGF) at $10 \mathrm{ng} \cdot \mathrm{mL}^{-1}$ increased HPASMC proliferation by 3.1 -fold. In the presence of CSE $10 \%$, PDGF $\left(10 \mathrm{ng} \cdot \mathrm{mL}^{-1}\right)$ increased HPASMC proliferation 3.5-fold, which was attenuated by BOS $(10 \mu \mathrm{M}), \mathrm{BQ} 123(10 \mu \mathrm{M})$ and BQ788 $(10 \mu \mathrm{M})$. Data are presented as mean \pm SEM of three independent experiments per condition. Ig: immunoglobulin. *: $p<0.05$ compared with respective control condition; ${ }^{*}: p<0.05$ compared with CSE group; " $p<0.05$ compared with CSE+PDGF group.

The ET system appears to have a large impact on the initiation and progression of lung vascular remodelling. In fact, exhaled breath condensate and circulating ET-1 levels are increased in COPD patients with $\mathrm{PH}$, and both are correlated with pulmonary systolic pressure [5]. Furthermore, animals exposed to CS show an increase in basal ET-1 levels and vascular contractility, which may contribute to the pulmonary pathophysiology associated with CS [26]. Recent studies performed on rat arteries originating from various tissues, such as brain, mesentery and kidney, conclude that CSE upregulates ETB and ETA expression by a mechanism that implicates the activation or phosphorylation of ERK1/2, p38, JNK, protein kinase (PK)C and NF- $\mathrm{BB}$ [9-11]. However, currently, no data about the effect of CS on ETR expression in human pulmonary arteries are available. In this study, we have observed for the first time that the CSE-stimulated

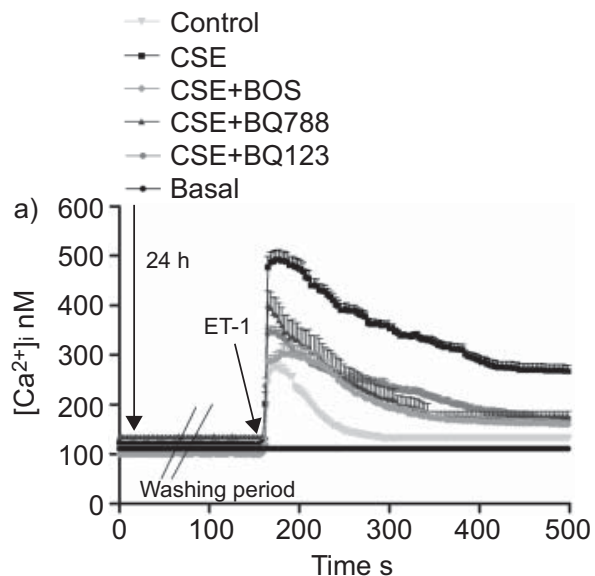

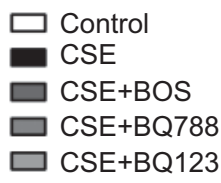

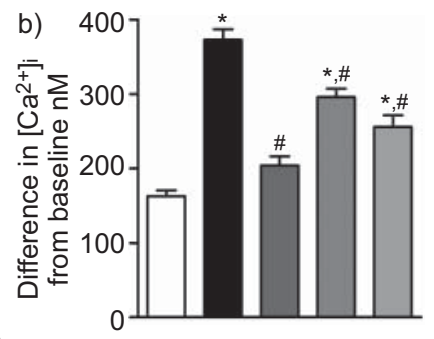

- Control

- CSE

$\rightarrow$ CSE+BOS

$\rightarrow \mathrm{CSE}+\mathrm{BQ788}$

$\multimap-\mathrm{CSE}+\mathrm{BQ} 123$

c) 150

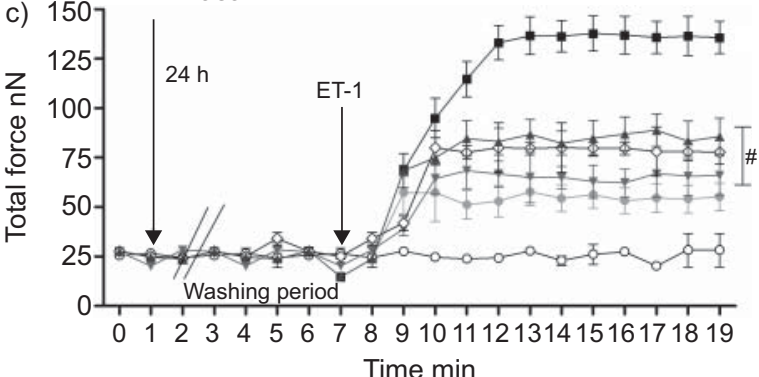

FIGURE 5. Cigarette smoke sensitises pulmonary artery smooth muscle cells to acute endothelin (ET)-1-induced intracellular calcium and cell contraction. Human pulmonary artery smooth muscle cells (HPASMCs) were exposed to 10\% cigarette smoke extract (CSE) in the presence or absence of bosentan (BOS) (10 $\mu \mathrm{M})$, BQ123 $(10 \mu \mathrm{M})$ or BQ778 $(10 \mu \mathrm{M})$ for $24 \mathrm{~h}$. a, b) Cells were washed three times with PBS and incubated with fura-2 acetoxymethyl ester for 30 min. Then, cells were stimulated with ET-1 $(10 \mathrm{nM})$. Data are presented as nanomolar intracellular free calcium concentration $\left(\left[\mathrm{Ca}^{2+}\right]_{\mathrm{i}}\right)$ in 12 cells per experiment, in a total of four experiments per condition. C) Disks with cultured HPASMCs were placed in the microscope and cells imaged with bright-field illumination. The time course of contractile response of HPASMCs challenged with ET-1 $(10 \mathrm{nM})$ is shown. Data are presented as total force exerted by the cell on the substrate in a total of six cells per condition. Data are presented as mean \pm SEM. *: $p<0.05$ versus control; $\#$ : $p<0.05$ versus CSE. 
a)
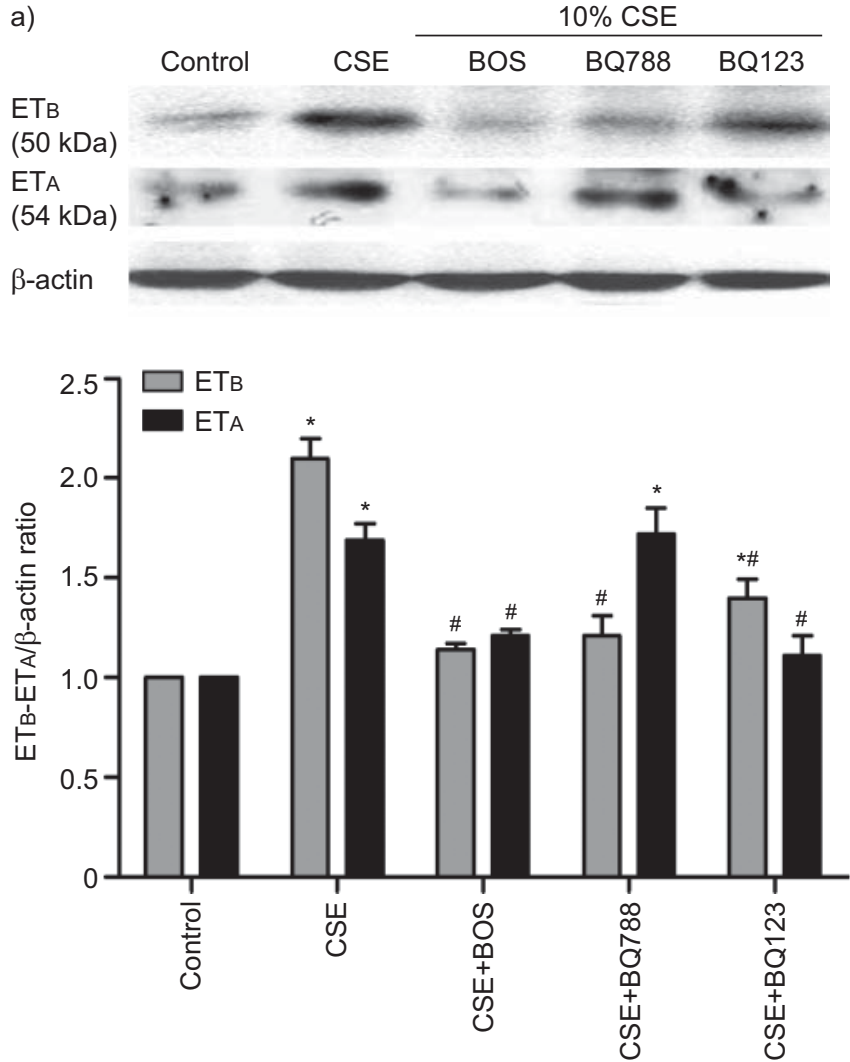

$\rightarrow$ Control

- CSE

- CSE+BOS

$\rightarrow$ CSE+BQ788

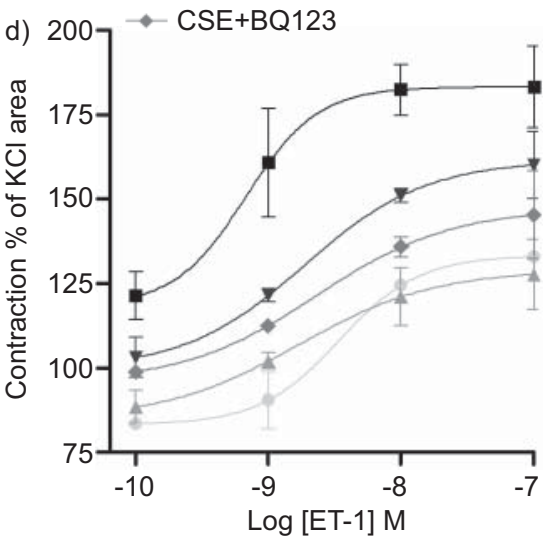

e) b)

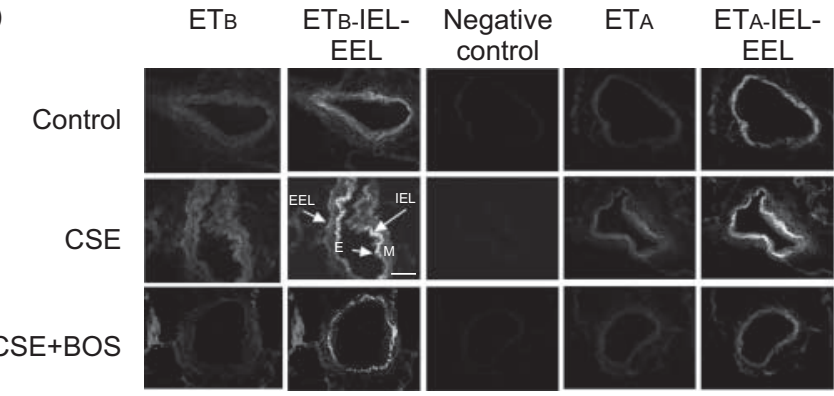

c)
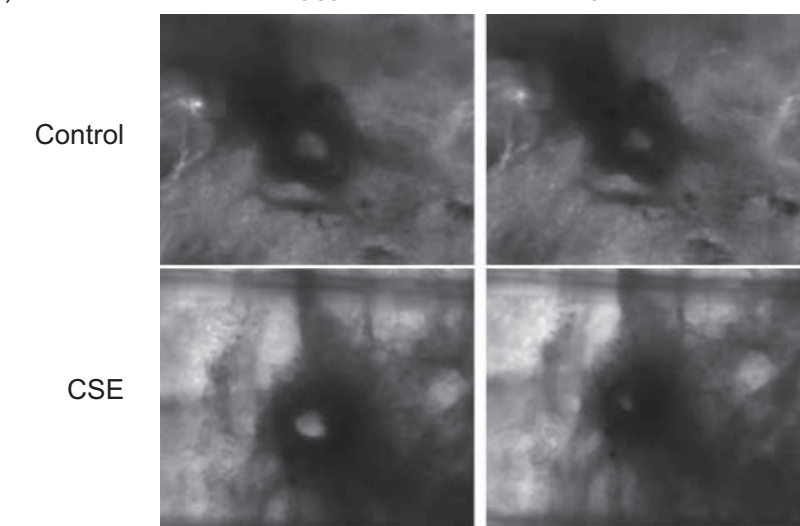

CSE+BOS
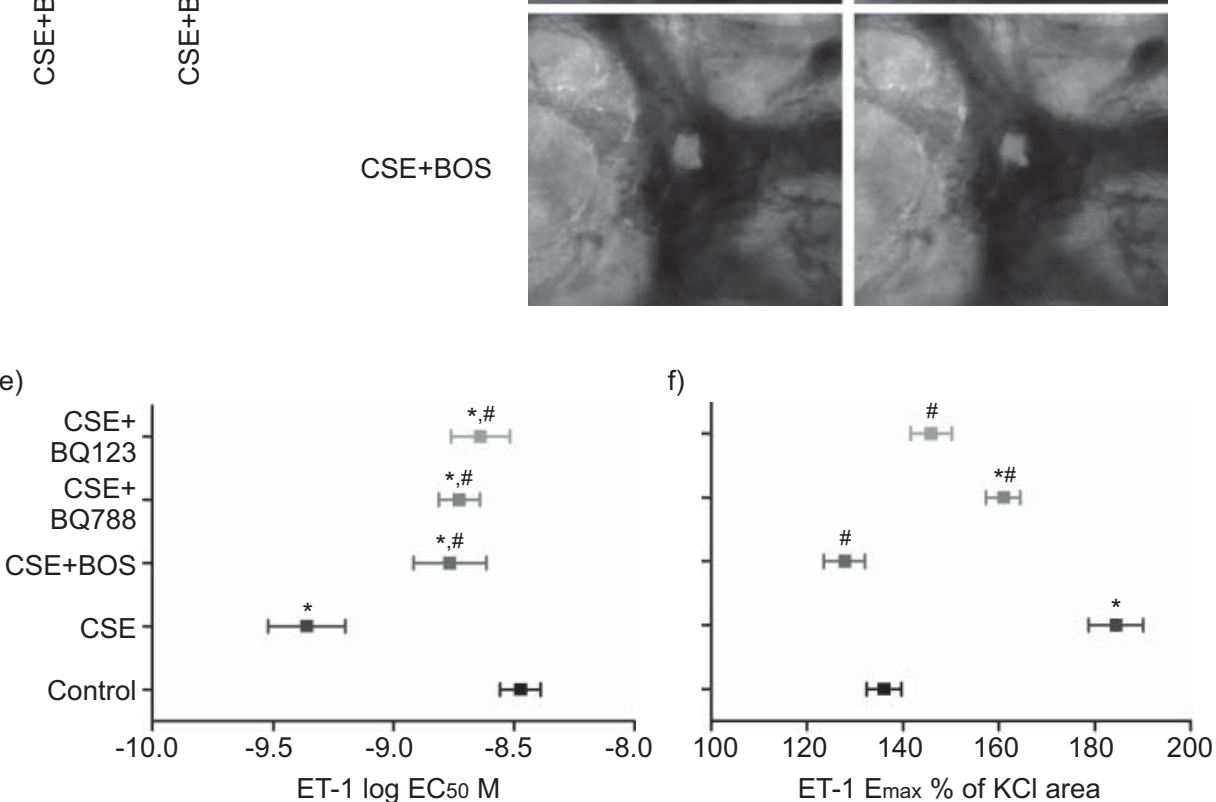

FIGURE 6. Cigarette smoke increases endothelin receptor $A$ and $B$ (ETA and ETB, respectively) expression in human small intrapulmonary arteries, which increase pulmonary vascular contractility in response to acute endothelin (ET)-1. Small human intrapulmonary precision-cut slices were exposed to $10 \%$ cigarette smoke extract (CSE) in presence or absence of bosentan (BOS) $(10 \mu \mathrm{M})$, BQ123 $(10 \mu \mathrm{M})$ or BQ788 $(10 \mu \mathrm{M})$ for $24 \mathrm{~h}$. a) Western blotting was performed to measure ETA and ETB protein expression. b) Precision-cut slices were fixed and immunofluorescence was performed for ETA and ETB with rhodamine secondary antibody. The internal elastic lamina (IEL) and external elastic lamina (EEL) were assessed by green autofluorescence. E: endothelial cells; M: smooth muscle cells. Scale bar=100 $\mu \mathrm{m}$. c) Representative images of the time-course human small pulmonary artery contraction in response to ET-1 under visible video microscopy. $\mathrm{d}-\mathrm{f}$ ) Concentration-dependent ET-1 contraction curves in two slices per condition of a total of three different patients per condition. Data are presented as mean \pm SEM of $a, b)$ three slices and $d-f$ ) two slices from three patients per condition. EC50: half-maximal effective concentration; Emax: maximal drug effect. *: $p<0.05$ versus control; *: $p<0.05$ versus CSE.

increase in ETB and ETA protein and gene expression can be counteracted by the dual ETR antagonist bosentan as well as by the selective ETA antagonist BQ123. In contrast, the selective ETB antagonist BQ788 only prevented ЕTB overexpression.
This process was explained, in part, by a feed-forward mechanism mediated by ET release. In this regard, CSE was able to increase supernatant ET levels that were consequently suppressed by bosentan and BQ123 and, to a lesser extent, by 

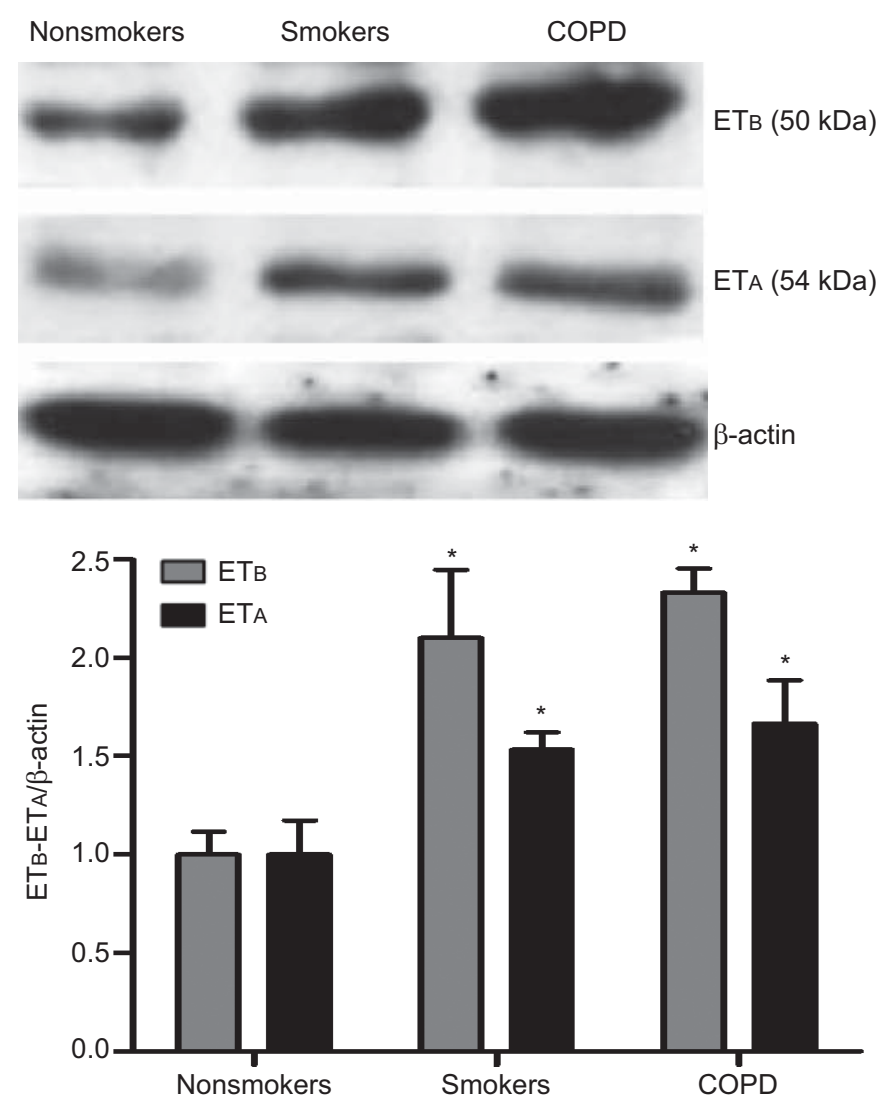

FIGURE 7. Endothelin receptor $A$ and $B$ (ETA and ETB, respectively) are upregulated in pulmonary arteries from smokers and chronic obstructive pulmonary disease (COPD) patients. Pulmonary arteries from nonsmokers, smokers and COPD patients were carefully isolated from tumour-free human lung tissue of surgical specimens. Total protein was extracted and probed for ETA and ETB antibodies by Western blot. Results represent the expression of ETA, ETB and the housekeeping protein $\beta$-actin from six nonsmokers, seven smokers and eight COPD patients. Densitometric data are shown as ETA and ETB protein expression relative to $\beta$-actin and normalised to nonsmoker expression. Data are presented as mean \pm SEM of densitometry of one Western blot per patient. *: $p<0.05$ versus nonsmokers.

BQ788. These results are apparently in contrast with previous reports where exposure to BQ788 and bosentan increased ET-1 mRNA in endothelial cells [27]. This effect was explained because extracellular levels of ET-1 are cleared via endocytosis of ETB; thus, its blockade impedes extracellular ET-1 clearance, inducing ET-1 upregulation. However, the results observed in this study were obtained in the totally different context of CSE exposure; CS increases ET release in endothelial cells and airway SMCs, as previously mentioned [28, 29]. In this study, we observed that the CS-induced ET release in HPASMCs was mediated by a mechanism including reactive oxygen generation, ERK1/2 phosphorylation and RhoA-GTP activation. This same mechanism has been also observed by our group in pulmonary artery endothelial cells [13]. Because blocking ETR is able to attenuate the CS-induced ROS, ERK1/2 phosphorylation and RhoA-GTP activation, it is reasonable to assume that ETR antagonism inhibits CS-induced ET release.

As with CSE, ET-1 incubation was also able to upregulate ETB and ETA expression in HPASMCs, which in turn confirms similar results observed in HPAECs [13]. Since endothelial cells are the main reservoir of ET-1, one could hypothesise that CS increases ET-1 in endothelial cells, which could interact with HPASMCs, increasing ETR expression. So, a direct effect of ET-1 on CS-induced ETR overexpression in HPASMCs cannot be ruled.

It is interesting to note that ET-1 stimulation induced a higher ETA expression than CSE (fig. 1a versus fig. 2c). Since ETA is mostly induced by ET-1, it may be presumed that the impotence of BQ788 in preventing CSE-induced ETA expression may be due to its low effect on CSE-induced ET release.

It is known that intracellular ROS may activate several intracellular pathways, such as PKC, different MAPKs (e.g. ERK1/2, p38 and JNK) and transcription factors (e.g. NF-кB) [30]. In fact, recent reports have shown that all these pathways are involved in CSE-induced ETB and ETA expression in rat basilar arteries [9, 10]. Furthermore, both CSE and ET-1 activate the reduced nicotinamide adenine dinucleotide phosphate oxidase complex to produce intracellular ROS [31, 32]. Interestingly, both the CSE oxygen species $\mathrm{H}_{2} \mathrm{O}_{2}$ and ET-1-induced intracellular ROS are mediated by the activation of ETA, since it has been shown that BQ123 inhibits them in fetal PASMCs [32]. In this study, the antioxidant NAC, bosentan and BQ123 attenuated the CSE-induced ROS, and ETB and ETA overexpression. In contrast, BQ788 did not influence the levels of ROS and ETA induced by CSE, so these results may explain, in part, the deficiency of BQ788 in affecting CSE-induced ETA expression. However, the ERK1/2 inhibitor PD98059 was sufficient in preventing the CSE and ET-1-induced ETB and ETA expression, which is in accord with previous reports in animal models $[9,11]$. In this regard, bosentan, BQ123 and, to a lesser extent, BQ788 prevented ERK1/ 2 phosphorylation, thus highlighting the role of ERK1/2 in CSEinduced ETR upregulation.

It is known that smokers and COPD patients display increased levels of expression of RhoA-GTP as well the downstream factor Rho-kinase, which is involved in endothelial dysfunction, vascular contractility and remodelling [33]. As we previously found in HPAECs [13], the ability of CSE to upregulate RhoA-GTP activity was preventable by bosentan, BQ123 and, to a lesser extent, BQ788 treatment. Moreover, the Rho-kinase inhibitor Y23670 prevented the CSE- and ET-1induced ETB and ETA upregulation, which implicates RhoAGTP activation in the process of ETR expression.

During the course of pulmonary vascular remodelling, PASMC proliferation contributes to intimal thickening. Previously, studies have positively correlated CS to vascular SMC proliferation [34] by a mechanism involving ERK1/2 activation. In this study, we observed that bosentan, BQ123 and BQ788 prevented HPASMC proliferation in a process involving both forms of ETR. Coupled with this, HPASMC proliferation was mediated by the activation of intracellular ROS, ERK1/2 and Rho-kinase, as well as by the autocrine ET action.

In other experiments, it was concluded that CSE exposure significantly increases acute ET-1-induced $\left[\mathrm{Ca}^{2+}\right]_{i}$ and cell contraction. Further research revealed, according to CSEinduced ETA and ETB expression, the inhibitory efficacy of bosentan, BQ123 and BQ788 on these CSE-derived outcomes. 
Based on these in vitro results, we attempted to translate the effect of CSE on human small intrapulmonary arteries to a precision-cut lung slice model. It is known that human pulmonary artery vascular remodelling occurs in small, resistant-type intrapulmonary vessels $(<3 \mathrm{~mm})$ and precapillary arteries (internal diameter $\sim 20 \mu \mathrm{m}$ ), which form part of the pulmonary vascular bed responsible for the pressure elevation observed in $\mathrm{PH}$ [3]. In the present study, precisioncut lung slices from small intrapulmonary arteries overexpressed ETA and ЕTв in vascular SMCs and endothelial cells secondary to CSE exposure. Bosentan and, to a lesser extent, BQ123 inhibited ETR upregulation, while BQ788 only attenuated ETB, which is in agreement with the in vitro cell data. An increase in pulmonary artery contraction secondary to acute ET-1 was an outcome of ETR upregulation and was suppressed by bosentan and, to a lesser extent, by BQ123 and B788. These results may be considered an approximation model of the in vivo conditions, since we found that isolated pulmonary arteries from smokers and COPD patients upregulates ETB and ETA.

Despite the novel mechanistic pathways studied here, we are aware of the study limitations. First, we conducted an in vitro acute $(24 \mathrm{~h})$ model of CS exposure, but progressive worsening of pulmonary haemodynamics in humans are induced only by chronic CS exposure over many years. Secondly, in vitro studies are not always representative of the in vivo findings, since a number of substances are released by CS and counteract different cell types at the same time; thus, results observed in isolated HPASMCs could be different in vivo. Thirdly, although we have found ETR overexpression in pulmonary arteries from smokers and COPD patients, none of them showed $\mathrm{PH}$, so whether COPD patients with $\mathrm{PH}$ have ETR upregulation or whether bosentan attenuates ETR upregulation in vivo remains unknown.

The results of this study indicate that the dual ETR antagonist bosentan effectively decreased the ETR overexpression elicited by CSE in HPASMCs and small intrapulmonary arteries. This direct inhibitory effect could explain the beneficial effects of bosentan in certain forms of disproportionate PH in COPD patients.

\section{SUPPORT STATEMENT}

This work was supported by grants SAF2008-03113 (J. Cortijo), SAF2009-08913 (E.J. Morcillo), and CIBERES (CB06/06/0027) from the Ministry of Science and Innovation and Health Institute Carlos III of the Spanish Government, and research grants (Prometeo/2008/045 and Emerging Groups GE-029/10) from the Regional Government ("Generalitat Valenciana").

\section{STATEMENT OF INTEREST}

None declared.

\section{ACKNOWLEDGEMENTS}

We are grateful for the valuable help of P. Bañuls and A. Serrano (Research Foundation of the Valencia University General Hospital, Valencia, Spain) in obtaining and isolating HPASMCs.

\section{REFERENCES}

1 MacNee W. Pathophysiology of cor pulmonale in chronic obstructive pulmonary disease. Part two. Am J Respir Crit Care Med 1994; 150: 1158-1168.
2 MacNee W. Pathophysiology of cor pulmonale in chronic obstructive pulmonary disease. Part one. Am J Respir Crit Care Med 1994; 150: 833-852.

3 Barbera JA, Blanco I. Pulmonary hypertension in patients with chronic obstructive pulmonary disease: advances in pathophysiology and management. Drugs 2009; 69: 1153-1171.

4 Haak T, Jungmann E, Raab C, et al. Elevated endothelin-1 levels after cigarette smoking. Metabolism 1994; 43: 267-269.

5 Carratu P, Scoditti C, Maniscalco M, et al. Exhaled and arterial levels of endothelin-1 are increased and correlate with pulmonary systolic pressure in COPD with pulmonary hypertension. BMC Pulm Med 2008; 8: 20.

6 Wackenfors A, Emilson M, Ingemansson R, et al. Ischemic heart disease induces upregulation of endothelin receptor mRNA in human coronary arteries. Eur J Pharmacol 2004; 484: 103-109.

7 Nilsson D, Wackenfors A, Gustafsson L, et al. Increased ETA and ETв receptor contraction in the left internal mammary artery from patients with hypertension. J Hum Hypertens 2008; 22: 226-229.

8 Bauer M, Wilkens H, Langer F, et al. Selective upregulation of endothelin B receptor gene expression in severe pulmonary hypertension. Circulation 2002; 105: 1034-1036.

9 Huang LH, He JY, Yuan BX, et al. Lipid soluble smoke particles upregulate endothelin receptors in rat basilar artery. Toxicol Lett 2010; 197: 243-255.

10 Sandhu H, Xu CB, Edvinsson L. Upregulation of contractile endothelin type B receptors by lipid-soluble cigarette smoking particles in rat cerebral arteries via activation of MAPK. Toxicol Appl Pharmacol 2010; 249: 25-32.

$11 \mathrm{Xu} \mathrm{CB}$, Zheng JP, Zhang W, et al. Lipid-soluble smoke particles upregulate vascular smooth muscle ETB receptors via activation of mitogen-activating protein kinases and NF-kappaB pathways. Toxicol Sci 2008; 106: 546-555.

12 Ortiz JL, Milara J, Juan G, et al. Direct effect of cigarette smoke on human pulmonary artery tension. Pulm Pharmacol Ther 2010; 23: 222-228.

13 Milara J, Ortiz JL, Juan G, et al. Cigarette smoke exposure upregulates endothelin receptor $\mathrm{B}$ in human pulmonary artery endothelial cells: molecular and functional consequences. $\mathrm{Br} \mathrm{J}$ Pharmacol 2010; 161: 1599-1615.

14 Milara J, Mata M, Serrano A, et al. Extracellular calcium-sensing receptor mediates human bronchial epithelial wound repair. Biochem Pharmacol 2010; 80: 236-246.

15 Cortijo J, Milara J, Mata M, et al. Nickel induces intracellular calcium mobilization and pathophysiological responses in human cultured airway epithelial cells. Chem Biol Interact 2010; 183: 25-33.

16 Wright JL, Churg A. Short-term exposure to cigarette smoke induces endothelial dysfunction in small intrapulmonary arteries: analysis using guinea pig precision cut lung slices. J Appl Physiol 2008; 104: 1462-1469.

17 Barberà JA, Peinado VI, Santos S. Pulmonary hypertension in chronic obstructive pulmonary disease. Eur Respir J 2003; 21: 892-905.

18 Higenbottam T. Pulmonary hypertension and chronic obstructive pulmonary disease: a case for treatment. Proc Am Thorac Soc 2005; 2: $12-19$.

19 Cottin V, Khouatra C, Lazor R, et al. Pulmonary hypertension therapy and COPD: still many questions to be answered. Eur Respir J 2009; 33: 450-452.

20 Valerio G, Bracciale P, Grazia D'Agostino A. Effect of bosentan upon pulmonary hypertension in chronic obstructive pulmonary disease. Ther Adv Respir Dis 2009; 3: 15-21.

21 Zacny JP, Stitzer ML, Brown FJ, et al. Human cigarette smoking: effects of puff and inhalation parameters on smoke exposure. J Pharmacol Exp Ther 1987; 240: 554-564.

22 Hampl V, Herget J. Role of nitric oxide in the pathogenesis of chronic pulmonary hypertension. Physiol Rev 2000; 80: 1337-1372. 
23 Holden WE, Kishiyama SS, Dong SP, et al. Endotheliumdependent effects of cigarette smoke components on tone of porcine intrapulmonary arteries in vitro. Toxicol Appl Pharmacol 1990; 104: 191-199.

24 Feyerabend C, Ings RM, Russel MA. Nicotine pharmacokinetics and its application to intake from smoking. $\mathrm{Br} J$ Clin Pharmacol 1985; 19: 239-247.

25 Su Y, Han W, Giraldo C, et al. Effect of cigarette smoke extract on nitric oxide synthase in pulmonary artery endothelial cells. Am J Respir Cell Mol Biol 1998; 19: 819-825.

26 Rahman MM, Elmi S, Chang TK, et al. Increased vascular contractility in isolated vessels from cigarette smoking rats is mediated by basal endothelin release. Vascul Pharmacol 2007; 46: $35-42$.

27 Farhat N, Matouk CC, Mamarbachi AM, et al. Activation of ETB receptors regulates the abundance of ET-1 mRNA in vascular endothelial cells. Br J Pharmacol 2008; 153: 1420-1431.

28 Fang Q, Zhao M, Ren G. [Effects of cigarette smoke extract on proliferation and ET-1 release of airway smooth muscle cells]. Zhonghua Yi Xue Za Zhi 1997; 77: 201-204.
29 Lee SD, Lee DS, Chun YG, et al. Cigarette smoke extract induces endothelin-1 via protein kinase $\mathrm{C}$ in pulmonary artery endothelial cells. Am J Physiol Lung Cell Mol Physiol 2001; 281: L403-L411.

30 Akki A, Zhang M, Murdoch C, et al. NADPH oxidase signaling and cardiac myocyte function. J Mol Cell Cardiol 2009; 47: 15-22.

31 Cheng SE, Lin CC, Lee IT, et al. Cigarette smoke extract regulates cytosolic phospholipase $\mathrm{A}_{2}$ expression via NADPH oxidase/ MAPKs/AP-1 and p300 in human tracheal smooth muscle cells. J Cell Biochem 2011; 112: 589-599.

32 Wedgwood S, Black SM. Endothelin-1 decreases endothelial NOS expression and activity through ETA receptor-mediated generation of hydrogen peroxide. Am J Physiol Lung Cell Mol Physiol 2005; 288: L480-L487.

33 Duong-Quy S, Dao P, Hua-Huy T, et al. Increased Rho-kinases expression and activity and pulmonary endothelial dysfunction in smokers with normal lung function. Eur Respir J 2011; 37: 349-355.

$34 \mathrm{Hu}$ J, Xu YJ, Zhang ZX, et al. Effect of cigarette smoke extract on proliferation of rat pulmonary artery smooth muscle cells and the relevant roles of protein kinase C. Chin Med J (Engl) 2007; 120: $1523-1528$. 